\title{
Dynamics of Creativity and Technological Innovation
}

\author{
Glorianna Davenport \\ Principal Research Associate \\ Head, Interactive Cinema, MIT Media Lab, Cambridge MA \\ Co-founder, Media Lab Europe, Dublin \\ Ali Mazalek \\ PhD Candidate \\ Research Assistant, Interactive Cinema, MIT Media Lab, Cambridge MA
}

\begin{abstract}
This article concerns the struggle between artistic expression and technological innovation. The perspective that is articulated is drawn from the work and of the Interactive Cinema group at the MIT Media Laboratory. Situated at the boundary of evolving technologies and media storytelling, research of the group iterates between shaping and presenting cinematic expressions using emerging technologies and developing the required tools and platforms to support its creation and delivery. This dynamic is integral to collaborative expression on large-scale projects, as well as in more individual research endeavors such as a current investigation which conjoins new tangible display technologies with interactive stories.
\end{abstract}

\section{Keywords}

Artistic expression, technological innovation, creativity, elastic movies, tangible displays, research laboratory.

"Interactive Cinema reflects the longing of cinema to become something new, something more complex, and something more personal, as if in conversation with an audience."

Glorianna Davenport

Founder, Interactive Cinema 1987

\section{Artistic Innovation, the Laboratory and Technology}

Throughout the ages, storytelling has been a principal mode of human communication. While the narrative act is shaped by sensory observation, cognitive interpretation, and the desire to share our experience with others, narrative expression becomes public and shared through appropriation of technology. Early technologies include picture formation, language, and the imitation of action. More recently optical, electrical and digital technologies have generated new media types and channels for narrative expression and distribution.

For four decades, my work in the expressive arts has been situated at the boundary of evolving technologies. Almost by definition, expressive technologies require a gestation period in order to gain the momentum required if they are going to become culturally dominant. This period is characterized by experimentation, debate and the exploration of economic opportunity. The struggle between expression and innovation, between old forms and new forms, between what has been and what will be, provide defining frameworks that allow a technology to mature. The research laboratory can play a significant role in such a debate. Both theory and the generation of prototype exemplars can be 
used to analyze and ground discussion surrounding new technology. Interactive television provides one example of this debate.

While the intellectual debate is helpful, the question remains as to whether prototype exemplars developed in the laboratory context are durable as artistic expression in their own right. Evaluation is difficult: if quality and durability is to be judged by the size of the audience (a paradigm for film and television), then laboratory work will be limited by public accessible to the distribution channel. The WWW, for instance, has offered more exposure to experimental cinema work than was possible for many experimental filmmakers in the past. Conferences, art festivals and museum exhibitions help a work gain exposure but generally these venues attract the already converted and provide only short-term exposure for a work. In addition, when research is driven by technical sponsorship, researchers generally work at the very edge of innovative technologies; these technologies may only be current for a few months or possibly a few years. Thus, unless significant resources are devoted to maintaining a presence for the work, the work may well disappear from public view not for want of popularity but for want of the technologies that make it accessible.

The MIT Media Laboratory was conceived around 1978 and founded in 1985. For almost two decades the laboratory has succeeded in maintaining a unique symbiotic partnership across the expressive arts and technical innovation. Expressive arts often provide the medium in which the technological kernel can be demonstrated in a compelling way. The laboratory's foremost organizational principal has been the atelier. The atelier allows each principal investigator to define and work on crazy, big ideas. Each investigator maintains some control over the continuity of the work through a fairly autonomous method of selecting 5 or 6 graduate students with whom she would like to work for the specified duration of their degree. A second organizational principle involves marketing the creative energy of the laboratory in ways that optimize time and attention to industrial sponsors, and at the same time optimize the progress of individual researchers. The goal is to allow big, surprising ideas to bubble up and make their way through the laboratory culture. This includes presentation broad groupings of sponsoring companies. By pooling of financial income, the lab takes a Robin Hood approach to the distribution of monies as needed.

As a founding member of this laboratory I have watched the rise and ebb of particular technologies and have had the opportunity to work with many talented young student researchers who contribute their own ideas about the future of the cinematic medium. While new technologies will inevitably transform distribution paradigms, mediate formative social practice and grow new market opportunities, I believe that the real grist of the cultural contribution lies in reframing the narrative paradigm itself. It is in relation to that mission that I have shaped the Interactive Cinema and the Story Networks research groups at the MIT Media Lab and Media Lab Europe respectively.

\section{Disruptive Technologies and Art Making}

My arrival at MIT in 1976 was reasonably serendipitous. Driven by my need for technological tools that could support my inquiry into everyday rural life and decision-making, I discovered in the Film Section a community of makers for whom the philosophical approach and the mode of practice focused on telling cinematic observational narratives of "life as it happens."

Established at MIT in 1970 and headed by Professor Richard Leacock, who is internationally recognized as the father of cinema-verite, the Film Section was widely regarded as one of the best, if not the best, documentary film school in the world. Offering a Master of Science in Visual Arts degree, the section attracted passionate filmmaking students from around the world who came despite the severe economic cost of tuition and of making their final film project. In addition to the graduate program, the unit ran popular filmmaking courses for MIT undergraduates and pursued a small research activity devoted to the development of a Super-8mm synchronous-sound film rig, a rig I chose to use on several occasions.

As a member of staff and a young filmmaker in this environment, I was acutely aware of the continual struggle between innovation and expression. Most students joined the Film Section program in order to make a "serious" thesis film. For most of them this meant shooting in $16 \mathrm{~mm}$ format where 10 minutes of processed $16 \mathrm{~mm}$ film cost about \$200; even with a reasonably low ratio of original to edited footage, this was an expensive medium! The intensity of the graduate culture was manifest throughout our laboratory: from excited conversations about the "best" stock to scenes of students practicing their "walking shots" with empty cameras on their shoulders, technique was all important. Both the experimental Super 8 rigs and black and white video rigs were available from around 1976 onwards; however, most of the students eschewed these "experimental" media. For the more adventurous students and staff these media were placeholders for the future. 


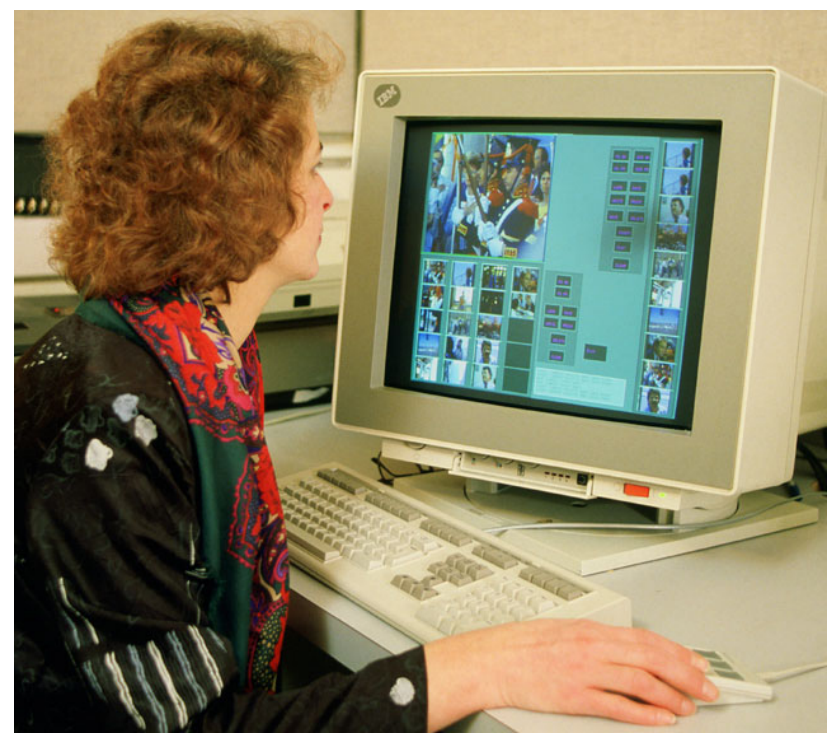

Figure 1: The custom interface to New Orleans in Transition, 1983-86, a 3-year cinematic case study of the city as it prepared for and hosted the 1984 World's Fair, provided students of urban planning access to 6 hours of video with 50 memorable characters and 5 interwoven story lines, significant text resources, and video editina capabilitv. (Photo Credit: MIT Media Lab)
In 1978, the first CAV optical videodisc player became available in the US; several of these were purchased by the Architecture Machine Group at MIT for use in computational media experiments. The player was unique among video devices because it had a built-in serial port. The CAV (constant angular velocity) format allowed the computer to access any individual frame of video. As the Film Section transitioned to the Film-Video section, a few of us realized that the future would be a computational video medium. In 1982, after 2 years of personal experimentation with programming these videodisc players, I wrote and was awarded a grant from the National Endowment for the Arts to make a 3 -year cinematic case study of a city in transition. The grant specified that two versions of the project which was to feature New Orleans as it prepared for and hosted the 1984 World's Fair would be released: the first, a television documentary, and the second, an interactive computer mediated version for the study of the urban environment. Somewhat ironically, the NEA had almost no interest in the interactive version. Luckily, Project Athena, the first large scale experiment to make network computers available to MIT undergrads, was interested and with their

support the New Orleans in Transition project became the first large scale documentary to be delivered over a computer network (Davenport 1987).

Even as I began shooting the film with Richard Leacock, I dove into the design and construction of a computational environment for cinema. At the time, no relevant exemplars or software existed. In order to provide the viewer with the ability to pro-actively explore, view, and contribute material, we specified an entirely novel application architecture and interface. This involved purchasing a rare and expensive video card $(\$ 12,000)$, evaluating commercially available databases (in the end, we implemented our own), developing a selection algorithm that maximized thematic continuity, and building our own random access video editing software so that students could edit video from the case study as part of their planning argument. In 1987 we ran a version of the project as part of an introductory course on urban planning. Students had access to 6 hours of video, 50 memorable characters and 5 interwoven story lines as well as to significant text resources. The reaction to the 5 -year effort was favorable, but the audience for the "interactive" version was extremely limited.

\section{The Emergence of a Laboratory Culture}

In 1985, in the midst of the New Orleans project, we moved along with 11 other groups from different parts of the campus into the newly completed I.M. Pei building. The laboratory soon became a melting pot for a broad spectrum of ideas. In 1987 I was invited to join the Media Lab faculty. True to his reputation for disrupting the status quo, Nicholas Negroponte suggested that I leave behind the work of New Orleans in Transition and articulate a new vision that could focus my work over the next 5-10 years. After some consideration, I named my new group "Interactive Cinema" with a mission to create cinema that was "more complex and more personal, as if in conversation with an audience."

The major difficulty that I then faced was how and what to teach. At the Film Section, we taught ilmmaking;

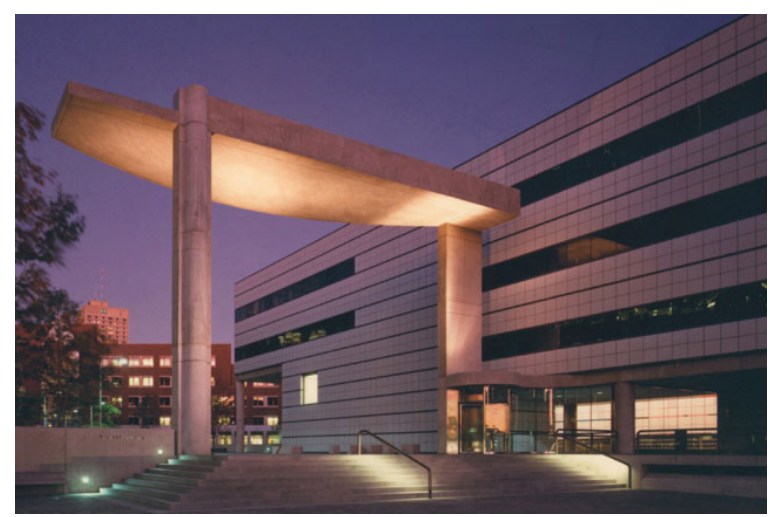

Figure 2: The Media Laboratory opened its doors in the Wiesner Building, designed by I.M. Pei, in 1985. (Photo Credit: Steve Rosenthal) 
students and staff went out and made their own movies. Computational narrative was bound to be more arduous, at least at the beginning. It had taken five years to produce and construct the computationally explorable cinematic fabric of New Orleans in Transition. Looking forward academically, it seemed unlikely that anything resembling a complex computational narrative could be accomplished in a single semester by a single student, even if that student was from MIT. I decided the best approach to my problem was to create a class in which all registered students would develop a single content project. This gave rise to "Workshop in Elastic Movie Time," a course which I taught for 8 years at MIT and internationally.

Strong creative work may be driven by inspiration and imagination; however, successful realization requires a longterm commitment to conscious activity of conceptualization, production and in the case of this new medium computational hacking. In designing a class around the creation of a single project, I faced some tricky challenges. The class attracted a mix of graduate and undergraduate students from diverse backgrounds: how could I motivate this group to act as a team? How could I ensure that each student gained the experience they were looking for? How could I recognize individual contribution without breaking some of the team dynamic? For several years structuring and leading this class became in itself a research agenda.

My first research assistant, Hans Peter Brondmo, who joined Interactive Cinema in February 1988 was a Macintosh aficionado and introduced me to an early version of Hypercard ${ }^{\mathrm{TM}}$. Together we decided that his research project would be to build a video friendly tool set in Hypercard ${ }^{\mathrm{TM}}$ for use in my fall class. In order to build tools, the developer needs to know what the tools will be used for. Partially inspired by News in the Future, a recently formed sponsor consortium, we determined that the class project would be a "hypermedia magazine."

Sometime in the summer of 1988, I settled on the Charles River as a focus for the hypermedia magazine. This would allow me to draw on my New Orleans experience, and would expose students to an environmental perspective of Cambridge, Massachusetts: what happens when a parking lot is placed on a flood plain? Why are there highways down both sides of the Charles River? Who actually runs the locks? As many of the students would have no prior experience in shooting video, I was also optimistic that the Head of the Charles race, which is held every year in October, would provide a content hook and would allow all the students to gain experience videoing. As the semester got underway, I gave another of my research students, Alan Lasky, the task of organizing the coverage of this event.

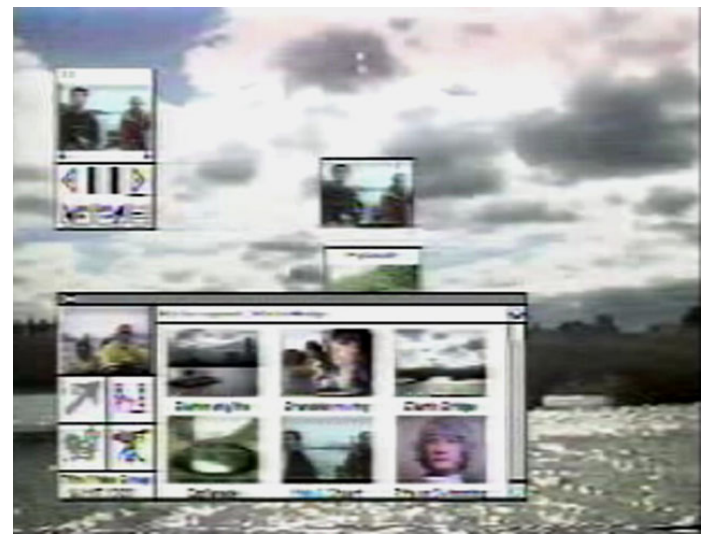

Figure 3: Created in 1988-9, Elastic Charles: a hypermedia magazine, provides an environmental perspective on the Charles River, a landmark that defines the geographic boundary between Cambridge and Boston, and invited the audience not only to navigate but also to create their own links using the "Elastic Tools" designed by Hans Peter Brondmo in Hypercard ${ }^{\mathrm{TM}}$.
The Elastic Charles, as it came to be called, remains a fun, content-rich example of early "interactive" media (Brondmo 1990). HP's "Elastic Tools" (which ran on Apple ${ }^{\mathrm{TM}} \mathrm{s}$ System 5) were groundbreaking. They allowed video sequences to be indexed by theme. Micons or motion picture icons, on which we hold a patent, provided a very early example of computationally displayed motion images. (Quicktime ${ }^{\mathrm{TM}}$, which was part of Apple ${ }^{\mathrm{TM}}$ 's System 6 was released almost 9 months after the first demonstration of the micon!) By displaying a 3 second loop of video, the micon proposed an exciting solution to the limitation of using a single-image icon to represent a video clip or sequence. The tools allowed the audience to create as well as follow video hyperlinks, thereby introducing the theme of audience as co-creator that remains one of the salient topics in much of today's media research.

While the tools were used to make several other projects, "Elastic Charles" became internationally recognized. Its popularity arose from the combination of "wow" technology and compelling video portrayal. The sequences of the Elastic Charles were charming and overall the project conveyed a strong environmental message. Not surprisingly, the class - having

created a work of high caliber - wanted it distributed. But how? The hardware set-up required to "play" the work was extremely specialized, relatively expensive and the software still had bugs. Over the next 4 months, Hans Peter honed the tools, while a small dedicated team of students and staff refined the existing content and developed additional content. In the summer of 1989, we released the production in the form of a videodisc, the "elastic tools" Hypercard ${ }^{\mathrm{TM}}$ stack, and the specification for an exact hardware set up. In addition to demonstrating our product in 
the laboratory and at many trade shows and conferences, we distributed 100 copies of the full system to sponsors or artists. The only requirement for receipt of a copy was that the recipient guarantee that he had the correct hardware. As with many of the productions that followed, this project ultimately went into cold storages because technology advanced.

The class proved to be an exciting mechanism for developing research ideas. Students from many different groups at the lab joined the course, bringing with them a broad expertise in video or in technology; rarely until the 1990's did we find students that were skilled in both. They also enjoyed working together. While the methods I used in creating the group project evolved year by year, some initial elements remained throughout: defining constraints for the production prior to the first classs; breaking the class into small groups of 3 or 4 students; requiring regular class presentation and discussion from each group; allowing for a final period of integration; emphasizing some public exhibition.

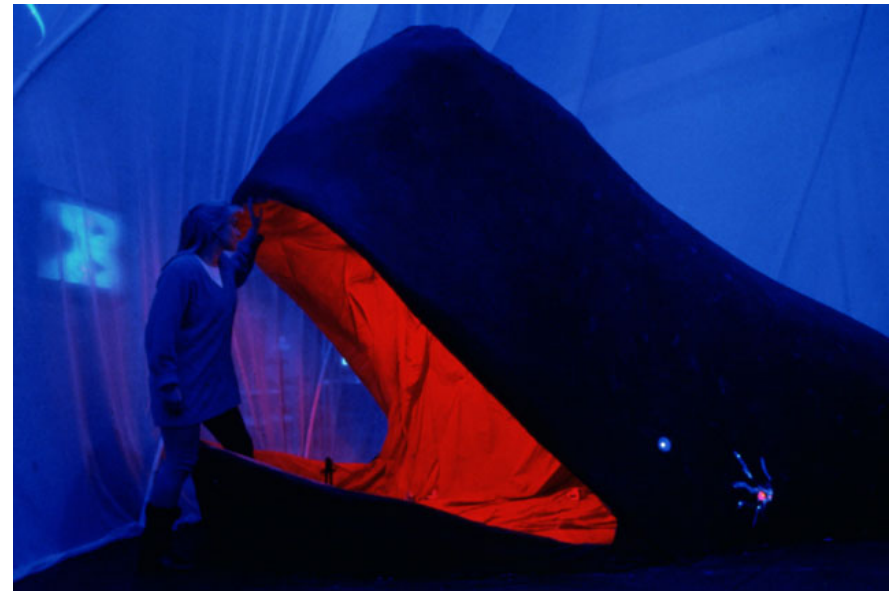

Figure 4: The Wheel of Life: an interactive transformational environment, invited the audience who took on the role of either "explorer" or "guide" to traverse three mythic spaces - water, earth and air. The production was open to the public for 10 days in Januarv 1992. (Photo Credit: David Tames)
The 1991 workshop was by far the most ambitious. Larry Friedlander, Professor of Literature at Stanford University had agreed to co-teach the workshop with me. When Larry and I met, we decided on three constraints for this class project: first, the production focus on the construction of an interactive transformational environment; second, the audience would consist of pairs of people - one person would be an explorer, the second person would be a guide; finally, the content of the narrative would take its inspiration from the Tibetan Wheel of Life with the individual modules being water, earth, air, fire (Davenport 1995a). The project was realized in the cube, a large space in the center of the Media Lab building that was initially designed for performance.

Larry's deep knowledge of dramatic narrative complimented my experience and in the end we were both fascinated by how to best create an audience-machine partnership that could inform

the experience of complex narrative? The energy the students devoted to this project was truly awesome. In the end we were only able to construct three spaces - water, earth, air. A scenario for each of these mystical, mythic spaces was first sketched with an emphasis on thematic and symbolic coherence; next each group worked more specifically on the relationship between explorer and guide; finally, each of the three theatrical spaces and its accompanying guide interface was designed and constructed. The project ran on an Appletalk network that while slow allowed rapid prototyping and iteration during the installation and performance periods.

Although the production was only open to the public for 10 days in January 1992, the project clearly captured the imagination of many people who experienced it. I think it is fair to say that this production was transformative for all student creators. In addition, perhaps because it involved partnership and exchange between audience members, it generated an unusual amount of interpretive reflection by the public during and after the experience. In this way, it championed the idea of the new media poet as a maker of culture.

\section{Evolution of the Channel}

Public exposure to these early experiments in interactive cinema were constrained by available technology. Therefore it is not surprising that when the early WWW browsers were released, much of the energy of Interactive Cinema turned to focus on the WWW as new channel for productions. Two works for the WWW from the mid-1995 serve as hallmarks for different reasons.

Ever since the New Orleans experiment, I had searched out a computational approach to a story engine that could use keywords to select and present sequences from a large cinematic database of "life as it happens" in a manner that ensured perceived narrative continuity. Unlike fiction, observational documentary is emergent and therefore not necessarily constrained by a dramatic arc paradigm. How could we translate this idea into an interface? 


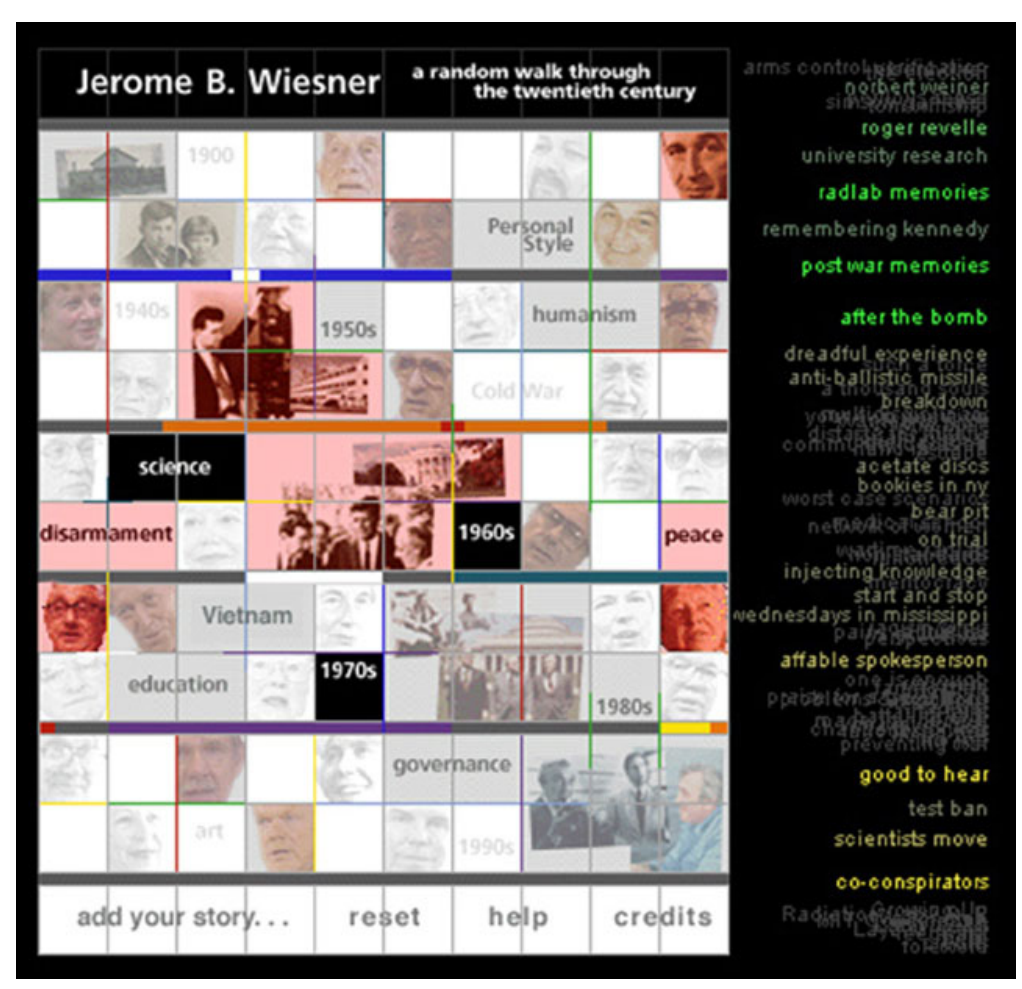

Figure 5: Using the World Wide Web as a distribution channel, this 1995 hyper-portrait invites viewers to explore the Twentieth Century through an extensible collection of stories and recollections about Jerome Wiesner.
In 1994, Michael Murtaugh used a spreading activation network to browse a database of sequences and descriptors that students had created around Boston's Big Dig. This proved extremely effective in maintaining thematic continuity. In 1995, Murtaugh recast this system so that it could run with video on the WWW. Like the Elastic tools of an earlier era, "Dexter" became a popular tool for people wanting to present video documentaries on the WWW (Davenport 1996). As Dexter was developed, Jerome B. Wiesner, former President of MIT and co-realizer, with Nicholas Negroponte, of the Media Laboratory, passed away. I was able to raise some funding which allowed me to create with Mike and other students a portrait of this well-revered figure. Over three months, I videoed many of JBW's former friends and colleages as they recalled short JBW narratives. The sequences were edited by Freedom Baird and in the fall of 1995, the hyper-portrait "Jerome B. Wiesner: a random walk through the $20^{\text {th }}$ Century" went live on the WWW where it continues to be viewed today (Davenport 1995b).

That same year, a Master's Student, Lee Morgenroth realized "Lurker," a fictional "thinkie" designed for the WWW (Morgenroth 1995). The work was experienced by groups of 6 audience participants who had signed up on the WWW to be "lurkers." The participants are dropped into a fictional scenario about a group of "hackers" at a certain unnamed institution of higher learning. The primary mode of interaction between the author and audience members and between audience participants is through the exchange of e-mail and posted video clips. This asynchronous mode of interaction allowed distributed participation but also required the story playout to take place over 5 days. The first video posting on the WWW lays out a mysterious disappearance. From then

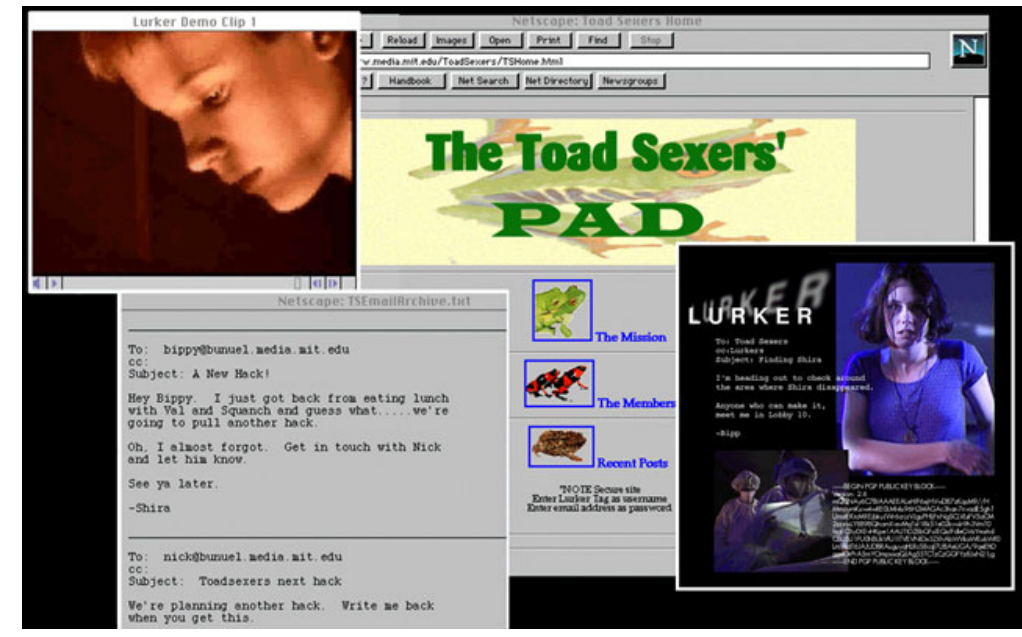

Figure 6: In Lurker, 1995, the audience took on the role of "lurkers," witnessed the disappearance of a hacker, and were invited to help solve the mystery. The piece used asynchronous communication to encourage on the audience of "lurkers" were asked to help the hackers solve the mystery; in the process they encounter several sub-problems. Lurker downplayed navigation and encouraged communication and cooperation among widely dispersed participants. The production ran continually off our servers for several months and was re-written and released for the Rotterdam Film Festival in 1998. 


\section{Cinematic Narrative for a Tangible Interface}

Like so many artists working in the digital medium, Ali Mazalek, now a Ph.D. candidate in the Interactive Cinema group, discovered an interest in technology through the expressive arts rather than the other way round. What follows is her story:

I had been making short videos using a Video-8 camcorder and a VHS tape deck for editing, and my search for new kinds of tools to support my creative goals brought me to the realm of digital technology. Despite shifting to a different medium, story form and content have always remained central in my work.

By 1994, computers had advanced to the point where even a relatively inexpensive desktop PC equipped with a video card and editing software could be used to make short movies. Working with this basic and still relatively cumbersome set of tools motivated me to take a software design class in my first year at the University of Toronto. My combined interest in technology and moviemaking landed me a job working with Professor Ron Baecker in the University's Collaborative Multimedia Research Group (CMRG). At the time, the group was developing an application for hierarchically structured movies - a kind of "word processor for movies" that integrated movie planning and pre-production with editing and post-production into a single easy-to-use software package (Baecker 1996). The idea of malleable movie structures led me to think about how emerging technologies are able to influence the story form, allowing artists and storytellers to push the limits of traditional narrative techniques.

While working at CMRG, I attended my first CHI (Computer-Human Interaction) conference, where I was introduced to the concept of Tangible Media. This area of interface design seeks to better integrate the dual worlds of bits and atoms by disseminating digital information into the objects, surfaces and spaces of the physical environment. The idea that digital information could break free from its confining box fascinated me immediately. I had been creating digital stories using screen-based graphical user interfaces (GUIs), but now tangible interfaces offered the potential for audiences to experience digital stories with a rich physical interface, without having to resort to keyboard and mouse-control. As they free themselves from the rigid linearity imposed by traditional narrative mediums, storytellers are designing structures that evolve over time or change based on audience input. As new sensing technologies enable digital information to move into tangible forms, stories need to make yet another leap in order to accommodate a new set of constraints. I joined the MIT Media Lab's Tangible Media Group in the fall of 1999 to try out some of my ideas. My first experiment in tangible storytelling, a project called genieBottles, taught me the basics of tangible story design (Mazalek 2001).

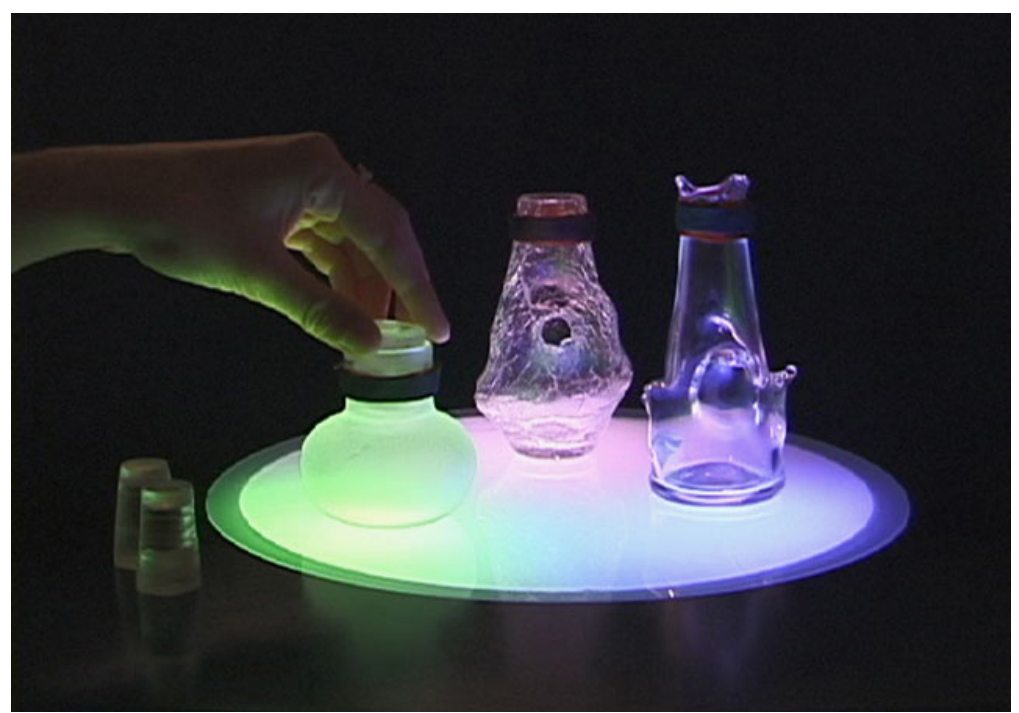

Figure 7: GenieBottles makes use of real-world objects as portals to a fantasy realm. Audience members release genies from glass bottles, and the story unfolds through their monologues and conversations. (Photo Credit: Ali
In genieBottles, real-world objects are used as portals to a fantasy realm. Like magic, genies are released from a set of glass bottles when you open them. Through their monologues and conversations, they gradually reveal the story of their entrapment, and the ways in which they hope to escape. The piece explores transparent and emotional interactions using physical interfaces that can weave themselves seamlessly into the fabric of everyday life. The glass bottles represent containers and controls for digital information, which is released in the form of audio whenever they are opened.

The genieBottles interface is tightly designed for a specific set of characters and a particular story form. This close coupling between the story world and the interaction objects provides a good basis

for narrative immersion. However it also imposes limitations on one of the major strengths of the digital medium: the inherent malleability of media content. In this sense, the shift to tangible interfaces represents a step back to a more rigid structure, and reveals a potential tension between the fixed physical form of real-world objects and the 
flexibility of digital information. As I learned from the genieBottles, one of the key principles for tangible story design is to find the correct balance between these two poles: the interaction constraints imposed by the properties of the physical medium on the one hand, and the flexibility of story content enabled by the digital medium on the other.

This search for balance led me to think about a new platform for tangible storytelling. At the time, the concept of an interactive workbench - a 2D augmented surface on which tagged physical objects could be sensed and tracked was becoming popular in the tangible interface community. By projecting graphics onto the tagged objects using a small LCD projector, a balance could be achieved between the rigid physical forms of the objects and the constantly changing digital information. In this way, the physical objects serve as handles and controls for the manipulation of large sets of dynamic media content. I designed the first version of a storytelling platform based on the interactive workbench concept in the final months of my Master's thesis in the Tangible Media group. This platform, called TViews, has several important implications for storytelling. First of all, it supports multiple points of control and has the size and scale of game-board, allowing collaborative story exploration and co-construction to become a driving force for the narrative. This social component represents a change from traditional screen-based storytelling approaches, which typically consist of either a large, relatively passive audience or a single active participant. Furthermore, the flexible nature of the platform's coupling between physical and digital elements allows it to support a variety of different storytelling applications, each providing a different story environment based on the underlying computational story structure, the projected graphics, and the particular set of physical manipulables. Finally, the platform provides a direct mode of navigation to the story world.

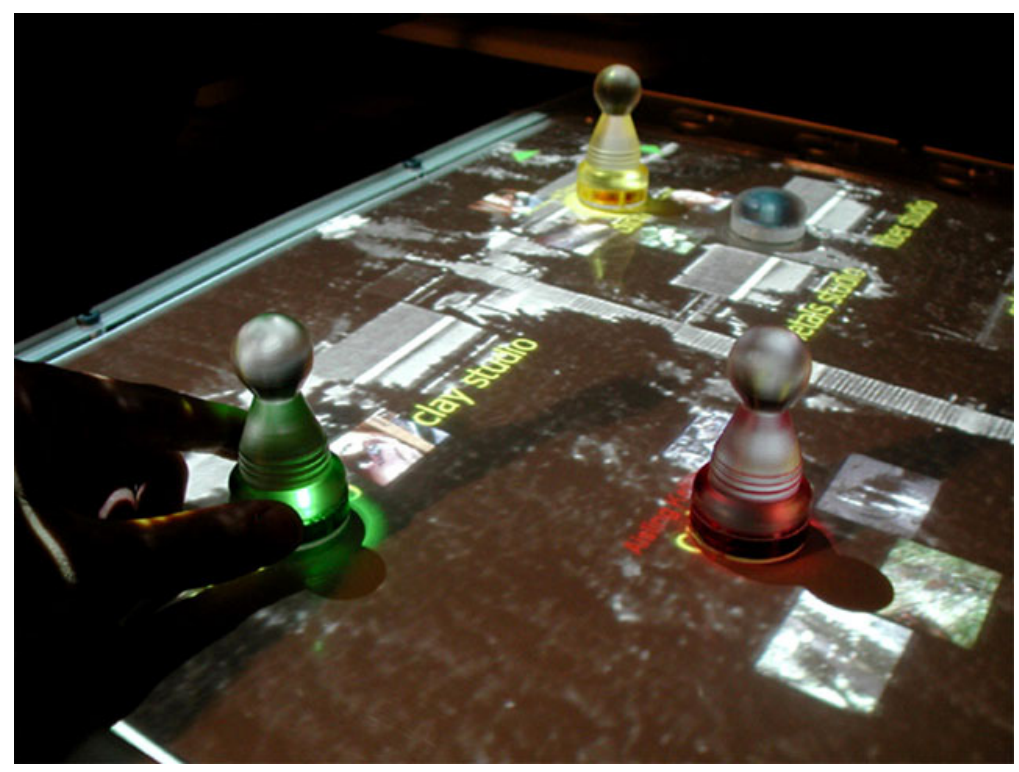

Figure 8: Created for the Digital Dialogues symposium held in September 2002, the first version of Tangible Spatial Narratives allows audience members to browse a database of documentary footage by manipulating small pawns on the surface of an interactive map. (Photo Credit: Ali Mazalek)
Since the completion of my Master's thesis, I have brought my tangible storytelling work to the Interactive Cinema group where I am expanding the set of story applications and content for the TViews platform. So far, the platform has been used for two major storytelling projects. The first was a narrative engine for multiple point-ofview stories called Tangible

Viewpoints, which was used by young adults at the Boston Museum of Science Computer Clubhouse for telling personal stories in November 2001 (Mazalek 2002). The second project, Tangible Spatial Narratives, creates narrative spaces in a physical form, allowing audiences to collectively reflect upon and navigate through complex spatially structured and multi-threaded stories. The system was used to document the stories of 65 participants across a dozen workshop spaces at the Digital Dialogues art and technology event held at the Haystack School of Mountain Crafts in Maine in the fall of 2002 (Kelliher 2003).

In recent months, I have also begun work on another spatial narrative project for the TViews platform: a fictional story landscape based on the St. Stephen's Green in Dublin, in which character stories play out across both space and time. As with my previous tangible systems, story content and audience experience remain central aspects in this new application, and an important question will be how to create a rich and sufficiently dense set of story threads to populate the landscape. One possible solution involves linking the tangible space to a parallel online representation, where visitors will create their own characters to inhabit the park space over given periods of time. In this way, the community of audience will be able to share in the role of story creators as well as story explorers. 


\section{The Harbingers of Culture}

Art and research are both the result of intelligent guessing. Cinema, expression that uses the medium of motion pictures to create narrative experiences, is being transformed through the evolution of communications technology. At the Media Lab, we use the tools of research to explore the medium in its becoming. Our research involves theory creation, tool building and the creation of expressive artifacts. The complimentary of these activities are often expressed in a cycle: imagine an innovation, build a prototype, realize a narrative using the innovation. When we have guessed well, the tools we build allow us to distribute an exemplar expression to the public, providing them with a novel, provocative experience through which they can reflect at multiple levels on who we are becoming. When the technology is harmoniously matched to the expression, we discover that the researcher is also a poet, a harbinger of future culture.

\section{Acknowledgements}

We would like to acknowledge the members of the MIT Film Section and the Interactive Cinema group, past and present, as well as the MIT Media Laboratory and its sponsors. We would also like to thank Maureen Thomas and Francois Penz for their support and interest in our work.

\section{References}

Baecker, R.M., Rosenthal, A., Friedlander, N., Smith, E., Cohen, A. (1996) A Multimedia System for Authoring Motion Pictures. In Proceedings of the $4^{\text {th }}$ ACM International Conference on Multimedia, Boston, MA, USA, 18-22 November 1996, ACM Press, pp.31-42.

Brondmo, H., Davenport, G. (1990) Creating and Viewing the Elastic Charles - a Hypermedia Journal. In McAleese, R., Green, C. (eds.) Hypertext: State of the ART. Intellect, Oxford, England, pp.43-51.

Davenport, G. (1987) New Orleans in Transition, 1983-1987: The Interactive Delivery of a Cinematic Case Study. In The International Congress for Design and Planning Theory, Education Group Conference Proceedings, Location, May.

Davenport G., Friedlander, L. (1995a) Interactive Transformational Environments: Wheel of Life. In Barrett, E., Redmond, M. (eds.) Contextual Media: Multimedia and Interpretation. MIT Press, Cambridge, MA, pp.1-25.

Davenport, G., Murtaugh, M. (1996) Dexter and the Evolving Documentary. In Proceedings of the $4^{\text {th }}$ ACM International Conference on Multimedia, Boston, MA, USA, 18-22 November 1996, ACM Press, pp.441-442.

Davenport, G., Murtaugh, M. (1995b) Jerome B. Wiesner: A Random Walk Through the $20^{\text {th }}$ Century. MIT Media Laboratory. http://ic.media.mit.edu/projects/JBW/ (Accessed 1 July 2003).

IC Website (2003) Interactive Cinema Group, MIT Media Laboratory. http://ic.media.mit.edu/ (Accessed 1 July 2003).

Kelliher, A., Mazalek, A., Davenport, G. (2003) Documenting Digital Dialogues: Engaging Audience in the Construction of a Collective Documentary Across Space and Time. In Proceedings of the $1^{\text {st }}$ International Conference on Technologies for Interactive Storytelling and Entertainment, Darmstadt, Germany, 24-26 March 2003, Springer-Verlag, pp. 248-259.

Mazalek, A. (2001) Tangible Interfaces for Interactive Point-of-View Narratives. MS Thesis, MIT Media Laboratory, Cambridge, MA.

Mazalek, A., Davenport, G. (2003) Interactive Cinema: A Retrospective. http://www.media.mit.edu/ mazalek/talks/rppr2003/ (Accessed 1 July 2003).

Mazalek, A., Davenport, G., Ishii, H. (2002) Tangible Viewpoints: A Physical Approach to Multimedia Stories. In Proceedings of the $10^{\text {th }}$ ACM International Conference on Multimedia, Juan-les-Pins, France, 1-6 December 2002, ACM Press, pp.153-160.

Morgenroth, L. (1995) Movies, Talkies, Thinkies: An Experimental Form of Interactive Cinema. MS Thesis, MIT Media Laboratory, Cambridge, MA.

SN Website (2003) Story Networks Group, Media Lab Europe. http://storynetworks.mle.ie/ (Accessed 1 July 2003). 